\title{
A crise do Direito e uma estratégia para sua superação: o exemplo das execuções fis- cais
}

\author{
The crisis of the Law and a strategy for its \\ overcoming: the example of the fiscal foreclosures
}

Renato Becho ${ }^{1}$

\begin{abstract}
Resumo: Em um contexto de diversas crises por que passa o país (política, econômica, ética, jurídica), este artigo almeja apresentar uma específica, a das execuções fiscais, que está bem documentada e pode exemplificar as demais. Aqui se sustenta que uma parte dela advém de uma estratégia de autoridades públicas de prolongar indefinidamente tais ações judiciais, ainda que contrariando preceitos legais claros. Todavia, os resultados não são positivos nem mesmo do ponto de vista econômico. Para tanto, buscou-se utilizar fontes dogmáticas clássicas, mas interdisciplinares, criando o ambiente propício para estudar a legislação e a jurisprudência de regência, notadamente uma decisão relevante do Superior Tribunal de Justiça. Nela, parâmetros anteriores deixaram bruscamente de ser
\end{abstract}

1 Graduado em Direito pela UFMG (1990), especialista em Cooperativismo pela UNISINOS/RS (1994), mestre (1997) e doutor (2000) em Direito pela PUC/SP e Livre-Docente pela USP (2008). Pesquisa pós-doutoral no King's College de Londres (2016). Professor na PUC/SP e Juiz Federal em São Paulo/ SP. E-mail: renatobecho@uol.com.br 
aplicados, o que é típico de uma época conturbada. Nesse ambiente, identificou-se como os procuradores fazendários, como advogados públicos, podem ser fundamentais na superação de crise. A conclusão a que se chega é pela estratégia de conferir maior segurança jurídica, valorizando o Estado Democrático de Direito.

Palavras-chave: crise do Estado; crise das execuções fiscais; estratégias públicas mal sucedidas; prazos de prescrição; reforço do Estado Democrático de Direito.

Abstract: In a context of various crises in the country (political, economic, ethical, legal), this article aims to present a specific, that of tax foreclosures, which is well documented and can exemplify the others. Here it is argued that a part of it come from a strategy of public authorities to extend indefinitely such judicial actions, although contrary to clear legal precepts. However, the results are not favorable even from an economic point of view. To develop that argument, it was sought to use traditional but interdisciplinary dogmatic sources, creating the right environment to study legislation and jurisprudence of regency, notably a relevant decision of the Superior Court of Justice. In it, previous parameters have abruptly ceased to be applied, which is typical of a troubled time. In this environment, it was identified how the attorneysin-fact, as public advocates, can be fundamental in overcoming the crisis. The conclusion reached is the strategy of giving greater legal security, valuing the Democratic Rule of Law.

Keywords: state crisis; a crisis of tax foreclosures; unsuccessful public strategies; limitation periods; strengthening of the Democratic Rules of Law. 


\section{Introdução}

No início de 2010, vivia-se euforicamente a impressão, aqui e em outros países, de que o Brasil finalmente havia encontrado o caminho do desenvolvimento. Havia crescimento econômico, com redução da pobreza e das desigualdades sociais; sediaríamos uma Copa do Mundo, com jogos por todo o país, e uma Olimpíada no Rio de Janeiro. A capa da revista britânica de negócios The Economist de 12 de novembro de 2009 ilustrou muito bem essa percepção, com o Cristo Redentor decolando do morro do Corcovado. Imaginávamos subindo na escala das sociedades civilizadas.

Passados apenas oito anos, a percepção - e os fatos - são outros. E não apenas por uma grave crise econômica, com aumento da pobreza e retorno evidente das desigualdades sociais aviltantes. Há uma gravíssima crise política, outra jurídica, uma crise ética.

O início da percepção de crise que se generalizou pode ser apontado em junho de 2013, quando uma expressiva parte da população tomou as ruas, de início contra o aumento de $\mathrm{R} \$ 0,20$ (vinte centavos) nas passagens de ônibus na cidade de São Paulo. Protestava-se contra algo difuso, mas que indicava um profundo descontentamento com os rumos da nação. $\mathrm{O}$ uso de ferramentas tecnológicas aproximou os descontentes e pegou os governantes de surpresa. Contudo, a insatisfação que pronunciavam foi se concretizando nas crises política e econômica, que logo passariam a ser incontestes.

Já em 2014 a economia não andou bem, mas afundou nos dois anos seguintes. A presidente eleita foi impedida de continuar governando; o novo presidente impôs uma agenda oposta aos votos que recebeu como vice-presidente, partícipe da chapa vencedora nas eleições. Seguiu-se a fragilização de direitos, o término abrupto de diversas políticas 
sociais. A crise política se profundou, com desdobramentos policiais. Altos dignitários do Estado estão presos junto com empresários partícipes do jogo econômico em escala global. Aumentou o descrédito na política e nos políticos, que são vistos cada vez mais como pessoas comprometidas com os financiadores de campanha e com o intuito maior de lesar os cofres públicos. A política se aproximou perigosamente do crime.

No âmbito do Direito - que será o centro deste estudo -, a sensação de crise advém do aumento acelerado de decisões judiciais em que a legislação não desponta como a principal fonte do Direito, bem como na fragilidade (ou inexistência) de fundamentação, indicando um aumento no ativismo judicial. Por outro lado, a Academia parece não ter elementos para explicar esses fatos, reproduzindo sistemas interpretativos que não explicam tais escolhas e, com isso, não oferece aos operadores do sistema mecanismos para prever tais decisões ou refutá-las com chance de êxito (mediante recursos manejados apropriadamente). A previsibilidade das decisões judiciais passa a ser equiparável à dos jogos de azar ou da prática de astrologia. Vai-se colocando, com razão, dúvida sobre a cientificidade do Direito.

Como não é possível tratarmos de todas essas crises nos limites de um artigo, faremos um corte metodológico e exporemos um ambiente em que seja possível a ilustração do quanto se apontou, notadamente quanto à crise do Direito, espelhada em decisões judiciais sem sólido embasamento legal e contrariando as regras de hermenêuticas apresentadas e explicadas pela doutrina. A escolha recaiu na tributação.

Os critérios para a seleção desse tema foram (i) a importância do item escolhido; (ii) a clareza ou facilidade de exemplificação da crise que se vive; e, por fim, a possibilidade de (iii) apontamento para uma solução que pareça razoável e factível, a produzir efeitos em um tempo aceitável. 
Utilizando o livro clássico de Norbert Elias O processo civilizador (1990) como pano de fundo, poderíamos explorar duas áreas de crise no Brasil com significativo embasamento teórico: o exercício dos monopólios da coerção física e da tributação. Quanto ao primeiro, a crise do sistema prisional nacional, que atingiu o terceiro maior contingente mundial, ${ }^{2}$ com a força do crime organizado dentro e fora dos presídios, poderia ser ambiente propício para a reflexão. Esse assunto é mais conhecido, ocupa as páginas dos jornais com frequências, e sobre ele já há uma percepção mais clara de caminhos para melhoria no quadro atual, ainda que de difícil concretização. Todavia, justamente por ser menos conhecido, optamos por levantar questões relacionadas à forma como a tributação tem sido exercida entre nós, buscando confrontar as normas jurídicas com a conduta dos agentes do Estado.

Dentro de diversos aspectos relacionados ao Direito Tributário que indicam grave crise, escolhemos o mais problemático e nítido, encontrando as execuções fiscais como ambiente propício para a ilustração da narrativa. Isso porque elas (i) correspondem à metade de todos os processos judiciais no país; ${ }^{3}$ (ii) oferecem exemplos em que referida crise pode ser exposta com clareza, pelo afastamento de decisões judiciais dos parâmetros estabelecidos pelo legislador, sem justificativa aparente; bem como (iii) pelo fato de que tais decisões não são sequer mencionadas pela doutrina.

Por fim, indicaremos qual o impacto dos desvios nas execuções fiscais na sociedade, conforme parâmetros apontados por estudiosos internacionais, nos termos como adiante demonstrado.

\footnotetext{
2 BRASIL, 2017a, s/p.

3 BRASIL, 2017b, p. 67 e 107.
} 


\section{A percepção de crise do Direito e seu foco simplista nas decisões judiciais}

Ao que parece, a crise do jurídico não é nova e nem é somente brasileira. Talvez ela apenas seja vista com mais nitidez. A assertiva decorre do quanto dito por Luis Recasens Siches:

A nossa época é um tempo de crise, de gravíssima crise, a terceira das grandes crises que registra a história universal, em que o fenômeno da crise se apresenta com formidável volume e radical intensidade. A crise é um mundo de transformação profunda, uma quebra das convicções fundamentais que regeram a vida do pretérito e a ausência de um novo sistema de convicções que se haja instalado real e efetivamente como estrutura da sociedade; portanto, é embaraçoso, um não sei o que esperar, uma perda de segurança na vida e de clareza e firmeza quanto às diretrizes de conduta. ${ }^{4}$

As sensações apontadas por Recasens Siches (quebra das regras que regeram o passado; ausência de um sistema instalado de novas convicções, insegurança jurídica e falta de clareza e firmeza nas diretrizes de conduta) apresentam-se atualmente com matiz forte o suficiente para serem incontestes.

A percepção de crise do Direito fica evidente com o livro "Por que tenho medo dos juízes (a interpretação/apli-

4 SICHES, 1965, p. 530-531. Tradução livre, nossa. No original consta: “No se debe olvidar que nuestra época es un tiempo de crisis, de gravísima crisis, de la tercera de las grandes crisis que registra la historia universal; y que el fenómeno de la crisis se presenta con formidable volumen y radical intensidad. La crisis es un mundo de transformación profunda, una quiebra de las convicciones fundamentales que rigieron la vida del pretérito y la ausencia de un nuevo sistema de convicciones que se haya instalado real y efetivamente como estrutura de la sociedad; por lo tanto, es azoramiento, un no saber a qué atenerse, una pérdida de seguridad en la vida y de claridad y firmeza en cuanto a las directrices de conducta". 
cação do direito e os princípios)" , de Eros Roberto Grau, em que o ex-Ministro do Supremo Tribunal Federal tece fortes críticas à atuação dos juízes, inclusive de seus antigos colegas de Pretório Excelso. Ele parte da deturpação criada em torno dos princípios jurídicos, que o leva, inclusive, a rever seu próprio pensamento. Em seguida, menciona a banalização dos princípios da proporcionalidade e da razoabilidade, que leva os juízes a "corrigir" o legislador. ${ }^{5}$ Deixando claro que o problema maior do momento da crise do direito atual está na conduta dos juízes, usurpando o que é, classicamente, a função do legislador, Eros Grau os repreende nos seguintes termos:

Isto é necessário afirmar bem alto: os juízes aplicam o direito, os juízes não fazem justiça! Vamos à Faculdade de Direito aprender direito, não justiça. Justiça é como a religião, a filosofia, a história. ${ }^{6}$

O cotejo da crítica à atuação judicial encontra eco no Código de Processo Civil de 2015. Por ele, o legislador importou mecanismos típicos do common law inglês, almejando

5 GRAU, 2013, p. 18. “Outra, na banalização dos 'princípios' (entre aspas) da proporcionalidade e da razoabilidade, em especial do primeiro, concebido como um princípio superior, aplicável a todo e qualquer caso concreto - o que conferiria ao Poder Judiciário a faculdade de 'corrigir' o legislador, invadindo a competência deste".

6 GRAU, op. cit., p. 19. Quanto aos princípios da proporcionalidade e razoabilidade, ensina: “O número de vezes nas quais esses dois 'princípios' são mencionados pela jurisprudência do STF Federal [sic] nestes últimos anos - seja determinando normas de decisão, seja conformando a produção de normas jurídicas gerais - impressiona muito, a ponto de podermos, ironicamente, dizer que ele deixa de ser um Tribunal constitucional para se transformar em um tribunal da proporcionalidade e da razoabilidade. A transgressão do sistema, agora sob o pretexto de aplicação desses princípios, é praticada à largada." (p. 136). O autor diz que isso não é fato novo, provando sua assertiva citando Jean Schmidt, Essai sur la Notion de Principe Juridique - Contribution à l'Étude des Principes Généraux du Droit en Droit Positif Français, em tese de 1955, o que reforça nossa afirmativa que a crise atual não é nova. Mas, repetimos, talvez ela possa estar, entre nós, mais evidente. 
reduzir a discricionariedade ou o ativismo judicial, além de cobrar o respeito às decisões judiciais, notadamente aquelas emanadas de cortes superiores (STJ e TSE) ou do Supremo Tribunal Federal. Se o CPC atingir os objetivos visados, passaremos a ter uma jurisprudência efetiva no Poder Judiciário, o que nos permitirá vislumbrar decisões previsíveis e tomadas em tempo razoável.

Mas há um componente que parece inegável e que não tem sido visto nas críticas ao ativismo judicial: quando o juiz profere uma decisão que não encontra embasamento legal, ele provavelmente agiu provocado por alguém (advogado). Do contrário, é de se esperar que o julgador, diante de dois embargos de declaração que indiquem, ambos, que a decisão foi dada sem suporte legal, a altere. Como será visto no item IV, abaixo, a Procuradoria da Fazenda Nacional não tem cumprido esse dever constitucional de agir dentro da legalidade (CF, art. 37), o que se transforma em um componente da crise jurídica pela qual estamos passando. Em outras palavras, como os fatos processuais comprovam, a crise do Direito também é uma crise da Administração Pública, que não cumpre a legislação de regência. Diante do ativismo judicial, no mais das vezes há um advogado, público ou privado, atuando para que o julgador se afaste dos quadrantes pré-estabelecidos.

\section{Sobre a essencialidade da tributação}

No intuito de justificar nossa escolha da exemplificação de crise jurídica pelas execuções fiscais, há que se resgatar a importância vital da tributação para o Estado. O objetivo é alcançado com apoio no clássico livro de Norbert Elias, $O$ processo civilizador (1990). Nele, o sociólogo explica o longo processo de refinamento das sociedades ocidentais, funda- 
mentando sua análise em documentos históricos e ponderações de como atitudes individuais refletem no coletivo, chegando a identificar comportamentos físicos, sociogenéticos e psicológicos de sociedades mais civilizadas. Nesse sentido, Elias indica como as pessoas em grupos mais civilizados se comportam preponderantemente como adultos, enquanto naquelas menos evoluídas nesse quesito apresentam comportamento mais infantilizado.

Mas o ponto de nosso interesse está na explicação de Norbert Elias para a evolução do feudalismo europeu para a formação e desenvolvimento dos Estados nacionais. Max Weber, na Sociogênese do Estado, ${ }^{7}$ apontou que uma das instituições constitutivas da organização social chamada Estado é o monopólio do exercício da força física coercitiva. Norbert Elias $^{8}$ acrescenta o monopólio da tributação, que durante o feudalismo era exercido pelo senhor feudal (portanto descentralizada), sendo que o monarca recolhia tributos quando havia uma despesa específica (uma guerra, a formação de dote de uma princesa, a necessidade de pagamento de resgate pelo monarca tornado cativo em outro reino etc.). A partir dos séculos XII e XIII, os tributos passam a ser instituídos e cobrados com regularidade pelo soberano, o que permitiu que os Estados nacionais pudessem arcar com outros serviços (além das guerras) custeados não mais pela exploração do patrimônio do monarca, mas mediante recolhimento de impostos.

Diversos pensadores avançaram na discussão da tributação como elemento essencial para o Estado, como Colin

7 Apud ELIAS, 1990, p. v. 1, p. 17. Para uma boa compreensão da importância de Weber para a compreensão do direito, veja-se o artigo de Alexander de Castro, "Max Weber e a história do direito: Fundamentos empíricos e historiográficos da sociologia jurídica weberiana”, 2016.

8 ELIAS, v. 2, p. 168 e s. 
Farrelly, citado por Onofre Alves Batista Júnior, Ludmila Mara Monteiro de Oliveira e Tarcísio Diniz Magalhães. ${ }^{9}$ No mesmo trabalho, os autores concluem pela pertinência das considerações de Thomas Piketty, em seu famoso $O$ capital no século XXI, no sentido de que:

[...] o direito tributário é chave no combate ao grave mal da desigualdade crescente e, ao contrário do que se poderia pensar, uma tributação robusta não só é compatível com uma posição liberal e com uma abordagem de direitos, mas é, na verdade, um imperativo da vertente mais avançada do liberalismo, que busca conciliar liberdade e igualdade, com vistas à realização da justiça. ${ }^{10}$

Dito isso, é o momento de questionarmos, focados no mencionado momento de crise: como está, em termos gerais, a tributação no Brasil? Vejamos no próximo item.

\section{A crise refletida nas execuções fiscais}

Justificada a essencialidade dos tributos para a formação do Estado, analisemos, agora, alguns aspectos gerais da tributação brasileira, com destaque para a crise das execuções fiscais. Ela será, conforme adiantado, um claro reflexo da crise instalada, cujo caminho de superação também ficará evidenciado.

A tributação encontra posição de destaque no nosso país. Ela representa em torno de $33 \%$ do $\mathrm{PIB}^{11}$ enquanto os EUA coletam $26,4 \%$ do PIB. ${ }^{12}$ Há uma relevante informatização na comunicação entre a Receita Federal e os contribuintes, que declaram tributos como o Imposto sobre a Renda e o Imposto sobre a Importação de produtos

9 BATISTA JÚNIOR, OLIVEIRA e MAGALHÃES, 2015, p. 223.

10 BATISTA JÚNIOR, OLIVEIRA e MAGALHÃES, 2015, p. 258-259.

11 BRASIL, 2016, s/p.

12 WIKIPEDIA, 2018, s/p. 
do exterior usando sistemas computacionais relativamente simples e acessíveis por computadores pessoais, inclusive portáteis (tablets e telefones celulares). Em 2017, 28,3 milhões de pessoas declararam o Imposto de Renda, o que representa aproximadamente $13 \%$ da população, um número expressivo. ${ }^{13}$

Um problema significativo é o excesso de programas de parcelamento, que desorganizam a tributação ao estimular a inadimplência, posto que muitos contribuintes que podem pagar suas obrigações deixam de fazê-lo aguardando a benesse legal. ${ }^{14} \mathrm{Um}$ estudo da Receita Federal indica que foram instituídos, nos últimos 18 anos, quase 40 programas federais de parcelamento de dívidas fiscais..$^{15}$ Esse aspecto pode ser reflexo da crise política mencionada anteriormente. Diversos contribuintes, notadamente pessoas jurídicas, deixam propositadamente de recolher tributos e passam a estimular os parlamentares a lançar leis que veiculem programas de parcelamento, onde eles conseguem obter melhores condições para quitar seus débitos com o fisco do que eram os originariamente estipulados. O excesso de programas de parcelamento, portanto, é um sintoma da crise política e não será, pelos pressupostos estabelecidos, desenvolvido aqui.

Outro problema, de ordem jurídica, é a crise das execuções fiscais. Ela está bem documentada no relatório Justiça em Números do Conselho Nacional de Justiça - CNJ. Na edição de 2017, que expõe e analisa os dados de 2016, colhemos importante síntese:

A cada ano, a publicação do Relatório Justiça em Números destaca o impacto negativo gerado pela fase de execução nos dados de litigiosidade do Poder Judiciário brasileiro, que acumula alto

13 BRASIL ECONÔMICO, 2017, s/p.

14 BRASIL, 2017e, $\mathrm{s} / \mathrm{p}$.

15 BRASIL, 2017c, s/p. 
volume processual e alta taxa de congestionamento. Esse volume dificulta a efetivação da tutela jurisdicional. ${ }^{16}$

No Justiça em Números consta que, em 2016, foram ajuizados 29,4 milhões de ações judiciais, sendo 3,241 milhões de execuções fiscais (aproximadamente 11\% do total de casos novos), das quais 3 milhões foram baixadas (pouco mais de 10\%). Nele também consta que haviam " 80 milhões de processos pendentes" no final de 2016, "sendo que mais da metade desses processos $(51,1 \%)$ se referia à fase de execução". Nesse universo, 75\% é "composta pelas execuções fiscais", que "representam aproximadamente 38\% do total de casos pendentes". ${ }^{17}$

Considerando que, em termos gerais, $11 \%$ dos novos processos ajuizados em 2016 eram de execuções fiscais, 10\% foram baixados e $38 \%$ de todos os feitos pendentes eram do mesmo procedimento, é correto apontar que as execuções fiscais correspondem à metade de todos os processos judiciais no país.

\section{A estratégia de cobrança das execuções fiscais e sua ineficiência}

Os dados apontados no item precedente indicam que a cobrança de execuções fiscais participa desse grave quadro de crise por que passa o Brasil e pode ilustrar bem se a crise é do direito positivo ou de outra natureza.

Um aspecto inicial é o da demora no ajuizamento de tais feitos, que recebeu uma roupagem linguística mais sofisticada. Veja-se o quanto colhido no mesmo Justiça em Números:

No quadro geral das execuções, o maior problema é a fiscal. O executivo fiscal chega a juízo depois que as tentativas de recupe-

16 BRASIL, 2017b, p. 107.

17 BRASIL, idem, p. 67 e 107. 
ração do credito tributário se frustraram na via administrativa, provocando sua inscrição na divida ativa. Dessa forma, o processo judicial acaba por repetir etapas e providencias de localização do devedor ou patrimônio capaz de satisfazer o credito tributário já adotadas, sem sucesso, pela administração fazendária ou pelo conselho de fiscalização profissional. Acabam chegando ao Judiciário títulos cujas dividas já são antigas, e por consequência, mais difíceis de serem recuperadas. ${ }^{18}$

Não se menciona, contudo, que a pouca efetividade da fase administrativa (cobrança indireta) é reflexo de sua limitação: ela se restringe à expedição, quando requerida, de certidão positiva de débito e à inclusão do nome do devedor no Cadastro Informativo de Créditos Não Quitados do Setor Público - CADIN. Tais providências funcionarão como impedimento para que o contribuinte devedor transfira bens de sua propriedade, participe de licitações públicas e obtenha crédito em bancos e agências de fomento. E nada mais. Pode-se dizer que a fase administrativa da cobrança do crédito tributário é totalmente passiva: a máquina pública espera o administrado provocá-la, é dizer: se ele precisar negociar bens, participar de licitações e requerer empréstimos, a fase administrativa de cobrança gerará algum efeito. Por outro lado, mesmo que o contribuinte tenha bens, mas não precise negociá-los, não precise participar de licitações ou mesmo de requerer empréstimos, essa fase administrativa não gerará efeito algum.

Além disso, há que se investigar se o direito positivo autoriza o mencionado ajuizamento de ações antigas, conforme citado acima. Em primeiro lugar, há que se recordar o princípio constitucional da eficiência administrativa, insculpido no art. 37 da CF. Aguardar os limitados efeitos da fase administrativa de cobrança de tributos parece contrariar o valor constitucional mencionado.

18 BRASIL, idem, p. 113. 
Mas não só. Concentrando nos tributos administrados pela Receita Federal do Brasil - RFB, que é o órgão mais importante nesse tema, há ordem explícita na legislação infraconstitucional que não dá suporte à referida demora no ajuizamento da ação. Segundo o Decreto-Lei n. 1.687/1979, art. 22, a RFB tem 90 dias para enviar o processo administrativo referente a tributo não pago para a Procuradoria Geral da Fazenda Nacional - PGFN, órgão encarregado da inscrição do débito em dívida ativa, expedição da respectiva CDA e ajuizamento da execução fiscal. Contudo, conforme apurado pela Controladoria Geral da União - CGU, raramente o prazo legal é cumprido. ${ }^{19}$ Assim, temos um grave problema: a Receita Federal não cumpre a legislação que estipula ordens para si, permitindo que a execução fiscal seja antiga quando proposta e ferindo o Estado de Direito.

O efeito sobre o crédito público é nefasto, pois, enquanto a administração tributária aguarda os fracos efeitos da cobrança indireta, o prazo de prescrição vai se aproximando, sendo que ele extingue a obrigação tributária, nos termos do Código Tributário Nacional, artigo 156, inciso V.

Essa situação deixa a Advocacia Pública (procuradoria fazendária) em uma situação difícil. Por um lado, o processo administrativo tributário chega a ela tardiamente, próximo da prescrição. É aqui que surge um momento crucial para o agente público: ele precisa fazer com que a Receita Federal agilize a entrega do processo administrativo que será ajuizado ou fazer com que o Poder Judiciário alongue o prazo prescricional.

Conforme será comprovado abaixo, a escolha da autoridade administrativa foi levar o Judiciário a alongar o prazo prescricional. Contudo, essa solução não auxiliou na melhora da arrecadação, pois esbarrou em problemas fáticos, não solucionáveis pela demora na atuação dos órgãos estatais.

19 BRASIL, 2013b, p. 23. 


\section{IV.1 Aumentando o prazo da prescrição intercor- rente via jurisprudência}

Conforme mencionado acima, vislumbramos que um aspecto muito interessante pode ser identificado como uma estratégia da Procuradoria Geral da Fazenda Nacional PGFN relacionada não à efetividade da cobrança do crédito tributário, mas centrando seus esforços na manutenção indevida do processo executivo. Essa estratégia não gera os efeitos para os quais a execução foi proposta, que é garantir a arrecadação fiscal. Para explicar essa análise, é imprescindível abordar, em termos gerais, alguns pontos principais das execuções fiscais.

Desde logo, é importante frisar que as execuções fiscais possuem um rito muito simples. A petição inicial normalmente ocupa uma lauda e é acompanhado apenas pela certidão de dívida ativa - CDA. Assim, não é difícil identificar que a peça vestibular possua 2 folhas de papel. Distribuída a ação, cabe ao juiz exarar a ordem de citação, apondo um simples "cite-se", que já encerra, em si, as providências a serem dadas em seguida (art. $7^{\circ}$ da Lei n. 6.830/1980, a Lei de Execuções Fiscais - LEF): citação pelas modalidades sucessivas (carta com aviso de recebimento, mandado por oficial de justiça e expedição de edital), penhora ou arresto de bens, seu registro e avaliação.

Um texto legal essencial para a boa compreensão do subsistema processual das execuções fiscais, conforme aprovado pelo Congresso Nacional, é conhecido como prescrição intercorrente, que vem positivado no artigo 40 e seus parágrafos, da mencionada LEF. Em termos gerais, não localizado o devedor ou bens penhoráveis, a execução irá para o arquivo sobrestado pelo prazo prescricional (que, nos termos do Código Tributário Nacional, art. 174, é de 5 anos), após o qual 
a ação será extinta. É aqui que se concentra a estratégia de manutenção das execuções fiscais mencionada acima. Para tanto, a PGFN encontrou no Superior Tribunal de Justiça STJ um parceiro fundamental.

Um momento vitorioso dessa estratégia foi a extensão do prazo de 5 para 6 anos para o reconhecimento da prescrição intercorrente, refletido na súmula n. 314 do STJ: “Em execução fiscal, não localizados bens penhoráveis, suspende-se o processo por um ano, findo o qual se inicia o prazo da prescrição quinquenal intercorrente". O problema é que, na legislação (Lei n. 6.830/1980), consta "prazo máximo de" um ano. ${ }^{20}$

Mas por que o legislador estipulou o prazo máximo de um ano para que o juiz determine o arquivamento dos autos? O motivo encontra-se no princípio da eficiência administrativa. O julgador não deve deixar a execução fiscal indefinidamente na secretaria da vara, aguardando eventual localização do devedor ou de bens penhoráveis. Os autos devem ir para o arquivo o mais rápido possível, sendo que a lei não veda, por exemplo, que isso ocorra no primeiro dia após o retorno dos autos da vista dada ao representante da fazenda pública, nos termos do $\S 1^{\circ}$ do artigo citado. Quanto mais eficiente for a serventia judicial, mais rápido o processo irá para o arquivo.

20 BRASIL, 1980. “Art. 40 - O Juiz suspenderá o curso da execução, enquanto não for localizado o devedor ou encontrados bens sobre os quais possa recair a penhora, e, nesses casos, não correrá o prazo de prescrição. $\S 1^{\circ}$ - Suspenso o curso da execução, será aberta vista dos autos ao representante judicial da Fazenda Pública. $\S 2^{\circ}$ - Decorrido o prazo máximo de 1 (um) ano, sem que seja localizado o devedor ou encontrados bens penhoráveis, o Juiz ordenará o arquivamento dos autos. $\S 3^{\circ}$ - Encontrados que sejam, a qualquer tempo, o devedor ou os bens, serão desarquivados os autos para prosseguimento da execução. $\S 4$ o Se da decisão que ordenar o arquivamento tiver decorrido o prazo prescricional, o juiz, depois de ouvida a Fazenda Pública, poderá, de ofício, reconhecer a prescrição intercorrente e decretá-la de imediato. (Incluído pela Lei n ${ }^{\circ} 11.051$, de 2004)" 
Como é cediço, a hermenêutica jurídica não deve ser baseada somente no texto legal. Entretanto, também é sabido que, para as palavras utilizadas pelo legislador não receberem a interpretação a partir de seu significado comum, há que se fundamentar suficientemente para convencer o leitor. Pois bem, no $\$ 2^{\circ}$ citado consta "prazo máximo" de um ano, e na súmula 314 do STJ a voz "máximo" foi suprimida. Assim, podemos identificar ao menos dois aspectos relevantes: (1) naturalmente, a súmula só existe porque essa interpretação foi provocada pelas procuradorias fazendárias. Do contrário, caberia aos procuradores atravessarem embargos de declaração e incentivarem os julgadores a decidirem nos termos da legislação; (2) a súmula foi além do decidido pelo legislador; (3) a súmula 314 do STJ faz com que haja um aumento no congestionamento de feitos apurado pelo $\mathrm{CNJ}$, descrito acima. Parte das execuções fiscais no país estão ativas como fruto dessa estratégia fazendária de manutenção dos feitos, ainda que contrariando a legislação.

É intuitivo identificar que uma parte das execuções fiscais que foram sentenciadas com base na interpretação gramatical do $\S 2^{\circ}$ do art. 40 da LEF foi ou será reformada pelos tribunais de segundo grau, fazendo com que retomem o seu curso, que não raro será o retorno ao arquivo sobrestado.

Sustentou-se, acima, que a interpretação dada pelo STJ para a supressão da voz "máximo" não convenceu. Prova da assertiva é que sua ratio decidendi foi reaberta, com o Recurso Especial n. 1. 340.553/RS, rel. Min. Mauro Campbell Marques, de onde três temas para reapreciação foram extraídos. ${ }^{21}$

21 TEMA 566 - Discute-se a sistemática para a contagem da prescrição intercorrente (prescrição após a propositura da ação) prevista no art. 40 e parágrafos da Lei da Execução Fiscal (Lei n. 6.830/80): qual o pedido de suspensão por parte da Fazenda Pública que inaugura o prazo de 1 (um) ano previsto no art. 40, $\S 2^{\circ}$, da LEF. TEMA 567 - Discute-se a sistemática para a contagem da prescrição intercorrente (prescrição após a propositura da ação) prevista no 
Como se infere, há muita insegurança jurídica envolvendo um assunto que poderia ser simples, acaso a legislação fosse aplicada sem a criação de interpretações criativas ou, dito de forma direta, se a legislação fosse aceita pelas procuradorias fazendárias e aplicada nos termos clássicos da hermenêutica legal.

\section{IV.2 Alterando o marco temporal para a prescrição via jurisprudência}

Outro caso interessante de manipulação da legislação a favor das fazendas públicas, com grande repercussão no número de execuções fiscais - ainda que com baixa repercussão arrecadatória -, foi a alteração do marco temporal interruptivo da prescrição. Para compreendê-lo, é relevante apresentar os contornos normativos envolvidos e tecer alguns comentários sobre o processo paradigmático no qual a jurisprudência foi alterada, com o afastamento do efetivo Estado de Direito.

Nos termos da Constituição Federal, cabe à lei complementar dispor, em normas gerais, a respeito da prescrição do crédito tributário. Seu cumprimento se dá pelo Código Tributário Nacional. Em sua redação original, de 1966, estabelecia o CTN que a interrupção da prescrição ocorreria com citação (art. 174, § único, inciso I). Esse Código não disciplina - e nem deveria fazê-lo - a própria citação, que fica a cargo do Código de Processo Civil.

art. 40 e parágrafos da Lei da Execução Fiscal (Lei n. 6.830/80): se o prazo de 1 (um) ano de suspensão somado aos outros 5 (cinco) anos de arquivamento pode ser contado em 6 (seis) anos por inteiro para fins de decretar a prescrição intercorrente. TEMA 568- Discute-se a sistemática para a contagem da prescrição intercorrente (prescrição após a propositura da ação) prevista no art. 40 e parágrafos da Lei da Execução Fiscal (Lei n. 6.830/80): quais são os obstáculos ao curso do prazo prescricional da prescrição prevista no art. 40, da LEF. 
Com a Lei Complementar n. 118/2005, uma mudança legislativa alterou o CTN e passou a considerar que "o despacho do juiz que ordenar a citação em execução fiscal" é que interrompe a prescrição. Qual o efeito dessa mudança? De fato, a redação originária oferecia segurança jurídica, pois exigia do credor (no caso as fazendas públicas) que ajuizasse a execução fiscal com alguma antecedência, para permitir que o Poder Judiciário a processasse (distribuição, autuação, remessa do distribuidor para o juiz, ordem de citação e sua efetivação etc.). É imprescindível apontar que o devedor tinha instrumentos para identificar a ocorrência da prescrição. Não sendo citado em cinco anos e alguns meses, poderia descartar os documentos fiscais anteriores a esse prazo, por exemplo. Com a mudança para "o despacho do juiz" ordenando a citação, o contribuinte perde totalmente o controle da situação. Ele não pode mais dispensar seus comprovantes fiscais dos últimos seis anos, por exemplo, pois ele pode vir a ser citado muitos anos após o despacho do juiz que determinou a sua citação.

A Lei Complementar n. 118/2005 já foi muito favorável ao Fisco e a seus advogados e prejudicial aos contribuintes e ao Direito, já que a segurança jurídica foi diminuída. Mas, como se não bastasse a benesse legal, uma alteração jurisprudencial fragilizou ainda mais o Estado de Direito e reforça a assertiva de que há uma estratégia para a manutenção das execuções fiscais, mas não a melhora na arrecadação.

No Recurso Especial n. 1.120.295/SP, relatoria do Min. Luiz Fux, o Superior Tribunal de Justiça afastou o Código Tributário Nacional com uma única palavra, chamando-o de "incoerente". A Corte, com isso, deixou de aplicar o art. 174 do CTN, e passou a aplicar o Código de Processo Civil, ainda que não se atentando para a Constituição, cujo artigo 146, conforme visto, não autoriza tal interpretação. Entretanto, 
para fragilizar ainda mais o direito, o STJ aplicou o artigo 219 do então CPC (de 1973) pela metade. De fato, apenas o $\S 1^{\circ}$ do texto processual foi levado em conta, sendo que os julgadores foram silentes quanto aos $\S \S 3^{\circ}$ e $4^{\circ}$, que infirmariam a decisão final que recebeu o efeito dos recursos repetitivos. ${ }^{22}$ Há dois aspectos muito interessantes nesse julgado, que induz à ideia de que há uma estratégia de prolongamento das execuções fiscais: o valor da dívida e os prazos envolvidos, o que foi alcançado com a análise efetiva dos autos, cuja cópia integral foi por nós manuseada.

22 Da longa ementa do julgamento, citamos apenas os pontos aqui em estudo. Confira-se: "13. Outrossim, o exercício do direito de ação pelo Fisco, por intermédio de ajuizamento da execução fiscal, conjura a alegação de inação do credor, revelando-se incoerente a interpretação segundo a qual o fluxo do prazo prescricional continua a escoar-se, desde a constituição definitiva do crédito tributário, até a data em que se der o despacho ordenador da citação do devedor (ou até a data em que se der a citação válida do devedor, consoante a anterior redação do inciso I, do parágrafo único, do artigo 174, do CTN). 14. O Codex Processual, no § $1^{\circ}$, do artigo 219, estabelece que a interrupção da prescrição, pela citação, retroage à data da propositura da ação, o que, na seara tributária, após as alterações promovidas pela Lei Complementar 118/2005, conduz ao entendimento de que o marco interruptivo atinente à prolação do despacho que ordena a citação do executado retroage à data do ajuizamento do feito executivo, a qual deve ser empreendida no prazo prescricional.[...]16. Destarte, a propositura da ação constitui o dies ad quem do prazo prescricional e, simultaneamente, o termo inicial para sua recontagem sujeita às causas interruptivas previstas no artigo 174, parágrafo único, do CTN. 17. Outrossim, é certo que "incumbe à parte promover a citação do réu nos 10 (dez) dias subsequentes ao despacho que a ordenar, não ficando prejudicada pela demora imputável exclusivamente ao serviço judiciário" (artigo 219, § 2 , do CPC). 18. Consequentemente, tendo em vista que o exercício do direito de ação deu-se em 05.03.2002, antes de escoado o lapso quinquenal (30.04.2002), iniciado com a entrega da declaração de rendimentos (30.04.1997), não se revela prescrita a pretensão executiva fiscal, ainda que o despacho inicial e a citação do devedor tenham sobrevindo em junho de 2002. 19. Recurso especial provido, determinando-se o prosseguimento da execução fiscal. Acórdão submetido ao regime do artigo 543-C, do CPC, e da Resolução STJ 08/2008”. BRASIL, 2010c, s/p. 
A origem do Recurso Especial n. 1.120.295/SP são os Embargos à Execução n. 2002.61.82.056792-7, proposto por Usitecno Indústria e Comércio Ltda. em face da Fazenda Nacional, que cobrava, em novembro de 2001, R\$ 24.683,41 (vinte e quatro mil, seiscentos e oitenta e três reais e quarenta e um centavos) na Execução Fiscal n. 2002.61.82004204-1, que tramitou na $11^{\text {a }}$ Vara Federal de Execuções Fiscais de São Paulo/SP. Nele fora penhorado um simples torno mecânico usado, de baixíssimo valor comercial. O valor da causa é importante, pois a defesa não poderia ser feita a qualquer custo. Por vezes, o devedor já não possui dinheiro para arcar com as despesas do processo, notadamente enviando advogado para atuar por ele em Brasília.

Outro aspecto é que os prazos envolvidos eram muito próximos. A dívida mais antiga tinha vencimento em 29/02/1996, sendo que a Certidão da Dívida Ativa foi expedida em 28/09/2001 e a execução fiscal foi ajuizada em 05/03/2002. Esse dado corrobora a mencionada demora no ajuizamento da ação, indicando que a administração tributária não estava cumprindo o princípio constitucional da eficiência.

Pois bem, conclui-se que, além da dívida ser pequena, a prescrição efetivou-se, pelas regras legais, poucos dias antes, quer do despacho do juiz determinando a citação, quer de sua efetivação, pois o Ministro indicou que ambos ocorreram em junho de 2002.

Outro processo poderia ter levado a conclusões diferentes. De fato, nos Embargos à Execução Fiscal n. 95.05045930 , que também tramitou na Justiça Federal em São Paulo/ $\mathrm{SP}$, o débito era relativo à declaração de Imposto sobre a Renda de 1966 (portanto, anterior ao CTN), ano-base 1965. O ajuizamento da ação ocorreu em maio de 1976 e logo recebeu o despacho de citação. Contudo, ela somente foi 
efetivada em outubro de 1994, portanto 18 anos após o início do processo e 29 anos após a ocorrência do fato gerador. A sentença não reconheceu a prescrição! O recurso, dirigido ao Tribunal Regional Federal da $3^{\mathrm{a}}$ Região (Apelação Cível n. 1999.03.99.087667-0/SP) foi julgado prejudicado, pois a certidão de dívida ativa foi cancelada administrativamente antes da apreciação do caso na Corte.

A pergunta, retórica, posto que sua resposta não é possível de ser dada, é se o Superior Tribunal de Justiça daria a mesma decisão do Recurso Especial acima mencionado em um feito ajuizado três décadas após o devido. Isto porque, não é difícil ajustar as situações fáticas quando muito próximas. Por outro lado, quando o STJ confere efeito de recurso repetitivo a casos como o acima descrito, como ocorreu, sua decisão passa a ser aplicada indistintamente a casos extremos.

Voltando ao Recurso Especial n. 1.120.295/SP, o ponto central do indigitado julgado, em síntese, é uma significativa mudança de paradigma: desde sua criação até aquela decisão, o STJ sempre aplicou o CTN. Em um feito, os Ministros mudam o paradigma, passam a aplicar o CPC, mas o fazem pela metade, considerand o o contido em um parágrafo $\left(\mathrm{o} 1^{\circ}\right)$ de um artigo (o 219), sem cuidarem de aplicar os parágrafos seguintes $\left(\S \S 2^{\circ}\right.$ a $\left.4^{\circ}\right)$ do mesmo texto.

A surpresa foi bem destacada por um advogado, Dr. Diogo Ferraz Lemos Tavares, que entrou com embargos de declaração, ainda que não fizesse parte do feito, com base no CPC/1973, art. 535, II. ${ }^{23}$ Registre-se que outros interes-

23 De sua petição, destacamos: "1.4. Registre-se que a possibilidade de intervenção é reforçada pela necessidade de garantir o acesso dos terceiros interessados ao Recurso Repetitivo, na medida em que, notoriamente, somente após a publicação do primeiro acórdão - invariavelmente acompanhada de ampla divulgação midiática - é que seguramente se tem conhecimento de que a matéria está em discussão. 1.5. O presente caso, aliás, é um perfeito 
sados passaram a atuar naquele caso, cuja decisão final não apenas contrariou a legislação pátria como passou a ter força normativa, dado o efeito dos recursos repetitivos.

Para aplicar integralmente o princípio da legalidade, deveria o procurador da Fazenda Nacional que atuava naquele processo, com base no artigo 37 da Constituição (princípios da legalidade, da moralidade administrativa etc.), ter apresentado embargos de declaração, indicando que a solução judicial contrariou a Carta da República (art. 146, III, b), bem como que não há regra de hermenêutica que autorize o julgador a fatiar a interpretação legal. Entretanto, a análise dos autos indicou o contrário, o completo silêncio da advocacia pública.

O que se seguiu foi a chamada jurisprudência defensiva. Tanto no próprio STJ, agora sob a relatoria do Ministro Gilson Dipp (o relator originário, Min. Luiz Fux, ascendera ao Supremo Tribunal Federal), quanto no STF, sob a relatoria do Min. Dias Toffoli, a ausência de pré-questionamento foi levantada. É dizer: como o argumento de que o artigo 146 da Constituição foi contrariado surgiu apenas em embargos de declaração, os recursos não foram apreciados. $\mathrm{O}$ motivo é lógico: até o resultado do recurso especial, em nenhum momento no processo ou na jurisprudência da Corte o CTN deixou de ser aplicado. Quando o foi, o único recurso cabível eram os embargos de declaração.

exemplo do que foi afirmado acima, uma que a discussão em torno do art. $219, \S 1^{\circ}$, do CPC não havia sido posto nos autos, nem mesmo no Recurso Especial, somente tendo surgido no acórdão ora embargado". BRASIL, 2010d, fls. 260-v. 


\section{IV.3 A estratégia não está funcionando}

Indicado, nos itens precedentes, a estratégia de alongar o prazo prescricional, via decisões judiciais, há que se perquirir se ela está funcionando e se ela é boa para a sociedade. A primeira parte da questão já parece ter sido respondida, considerando que as execuções fiscais respondem pela metade dos processos judiciais (vide item III, supra).

Por outro lado, a recuperação de créditos tributários federais via execução fiscal é muito baixa. O órgão responsável pela cobrança judicial, a Procuradoria Geral da Fazenda Nacional - PGFN, informa que, em 2016, foram recuperados $\mathrm{R} \$ 14,54$ bilhões da Dívida Ativa da União, que totalizou no final do mesmo ano R $\$ 1,84$ trilhão. ${ }^{24}$ Isso significa que foram recuperados menos de $0,8 \%$ do total cobrado.

Considerando os diversos programas de parcelamento já mencionados, a análise do sucesso na cobrança de tributos via execução fiscal, comparando-se um ano com outro, fica muito difícil. Todavia, ainda que impreciso, é possível vislumbrarmos os efeitos do Recurso Especial n. 1.120.295/ SP, cuja decisão é de maio de 2010.

A PGFN arrecadou, em 2010,0,62\% da dívida ativa sob sua responsabilidade. Em 2011 foram 1,37\%. ${ }^{25}$ Conforme dito acima, em 2016 foram 0,8\%. Vejamos outros dados.

O relatório Justiça em Números de 2010, referente aos processos de 2009, foi o primeiro ano em que se destacaram as execuções fiscais das demais execuções. Dos dados globais, envolvendo as Justiças Federal, Estadual, Trabalhista e Eleitoral, eram 86,6 milhões de feitos em tramitação, sendo que 26,9 milhões eram execuções fiscais, um terço do total.

24 BRASIL, 2017d, s/p.

25 BRASIL, 2010b, p. 14. 
A Justiça Federal recebeu 288 mil novos processos dessa classe, baixou $10 \%$ deles e terminou o ano com um estoque de 2.609.866 desses processos. A taxa de congestionamento ficou em $90 \%{ }^{26} \mathrm{Em} 2013$, já se nota o aumento proporcional das execuções fiscais, que passaram a representar $40 \%$ do estoque de processos pendentes. ${ }^{27}$

Focando no estoque de execuções fiscais, em 2009 eram em torno de 33\% dos feitos; em 2012 eram 40\% e, conforme dito no item III, acima, em 2016 eram $38 \%$. Comparando com a porcentagem dos valores recebidos, não se pode afirmar que há uma situação linear na recuperação dos créditos, mas houve aumento proporcional no número de execuções fiscais, o que confirma a estratégia dos exequentes nas últimas décadas, baseada na manutenção dos processos, ainda que ilegalmente.

A situação aqui descrita exemplifica o cumprimento das leis no nosso país e os resultados assim auferidos. Ela foi mensurada e comparada globalmente pelo Projeto Justiça Global, que listou o Brasil, em 2015, dentre 99 nações, no $46^{\circ}$ lugar. ${ }^{28} \mathrm{Em} 2016$, dentre 113 países, ficamos em $52^{\circ}$ no quesito "cumprimento da lei" (Estado de Direito). ${ }^{29}$

26 BRASIL, 2010a, p. 14-15 e 43-44.

27 BRASIL, 2013a, p. 299. Nas “Considerações finais” do Justiça em Números 2013, colhemos que: "A análise da série histórica traz à tona, novamente, o peso exercido pelos processos de execução fiscal, que representam $40 \%$ do estoque de processos pendentes e apenas 13\% dos casos novos. A principal dificuldade consiste na redução do estoque dos processos de execução fiscal, visto que, mesmo com esforços empreendidos em 2011 e 2012 para aumentar o número de processos baixados, o quantitativo de processos em tramitação permanece subindo. A taxa de congestionamento na execução fiscal é de $89 \%$, ou seja, de cada 100 processos em tramitação, 11 são baixados no decorrer do ano. Além disso, $8 \%$ dos processos de execução fiscal em tramitação foram sentenciados em 2012." BRASIL, 2013a, p. 299.

28 WORLD JUSTICE PROJECT, 2015, p. 6.

29 WORLD JUSTICE PROJECT, 2016, p. 5. 
E, como aqui sinalizado, a estratégia de fragilizar o Estado de Direito não tem resultado em melhoras efetivas e duradoras na arrecadação. E ela produz efeitos negativos na sociedade, como será visto no próximo item.

\section{Por que as Nações fracassam?}

O instigante livro Por que as nações fracassam de Daron Acemoglu, professor de Economia do Massachusetts Institute of Technology - MIT, e James Robinson, professor de Administração Pública de Harvard, indicam a resposta sobre os efeitos da quebra do Estado Democrático de Direito para as sociedades. Analisando cidades ou Estados muito próximos geográfica, histórica e culturalmente, como a cidade de Nogales na fronteira entre os EUA e o México, as Coreias do Sul e do Norte ou Berlim Ocidental e Oriental antes da queda do Muro, a conclusão a que os autores chegaram é que a diferença entre países que prosperam e os que fracassam, no sentido econômico e humano, está na força de suas instituições atuarem em favor do bem estar coletivo, e não no benefício de um pequeno grupo que está no poder.

As instituições de países desenvolvidos são "inclusivas", expressão que podemos resumir, em linguagem jurídica, como promotoras do Estado Democrático de Direito. As instituições dos países que fracassam são "extrativas", no sentido que beneficiam apenas os detentores do poder, o que vai minando não apenas a crença no Estado e no Direito, mas no próprio ânimo das pessoas, que identificam que não vale lutar por uma vida melhor, criando empresas e empregos, por exemplo, se, por atos arbitrários, seus direitos não são reconhecidos.

Mencionando figuras emblemáticas do mundo econômico dos Estados Unidos, os autores asseveram: 
À medida que influenciam comportamentos e incentivos na vida real, as instituições forjam o sucesso ou fracasso dos países. [...] Esses empreendedores tinham a convicção, desde o começo, de que os projetos dos seus sonhos tinham condições de ser implementados: confiavam nas instituições e no estado de direito por elas engendrado, e nada tinham a temer em relação à segurança de seus direitos de propriedade. Por fim, as instituições políticas lhes asseguravam estabilidade e continuidade. De um lado, garantiam que não havia risco de um ditador assumir o poder e mudar as regras do jogo, desapropriando-os de sua riqueza, aprisionando-os ou ameaçando sua vida e meios de subsistência [...]. ${ }^{30}$

Nesses termos, em nosso país, ainda que não tenhamos exatamente a garantia de que um ditador não assumirá o poder, não há motivos para dizer que confiamos nas nossas instituições e no Estado de Direito, ao menos no que concerne às execuções fiscais. As regras jurídicas mudam durante $o$ processo, levando a uma profunda insegurança.

Finalizando, atentemos para as lições de T. H. Huxley, expondo os avanços científicos entre os anos 1837 a 1887:

A diminuição ou remoção da ignorância ou preconceito local, a criação de interesses comuns entre os povos amplamente separados e o fortalecimento da organização da comunidade contra a anarquia política ou social, assim efetuados [pelas descobertas científicas], exerceram influência sobre a fortuna presente e futura da humanidade, cujo pleno significado pode ser adivinhado, mas que ainda não pode ser estimado em seu pleno valor. ${ }^{31}$

30 ACEMOGLU, ROBINSON, 2012, s/p (e-book).

31 HUXLEY, 1889, s/p (ebook). Tradução livre, nossa. No original consta: "The diminution or removal of local ignorance and prejudice, the creation of common interests among the most widely separated peoples, and the strengthening of the forces of the organization of the commonwealth against those of political or social anarchy, thus effected, have exerted an influence on the present and future fortunes of mankind the full significance of which may be divined, but cannot, as yet, be estimated at its full value". 
Com essa lição, identifica-se que é necessário novo esforço acadêmico para a consolidação do Estado Democrático de Direito como caminho para a superação das diversas crises por que passa o país. Há um grande desafio para os profissionais do Direito, que é utilizar os mecanismos de sua ciência para, ao lado da Sociologia, da Economia, da Filosofia, enfim, das Ciências Sociais, fortalecerem o Estado e a Sociedade.

\section{A estratégia para superar a crise do Direito e das execuções fiscais}

Pelo estudo aqui desenvolvido, observou-se que a crise por que passa o Direito não é nova nem apenas local. Ela advém de novos valores, novos paradigmas, com os quais se buscam superar diversos problemas nacionais.

Com base na importância da tributação, elemento fundamental do Estado, optou-se por concentrar a análise nas execuçoes fiscais, documentada como um dos problemas do Poder Judiciário brasileiro. Todavia, levantou-se a hipótese de que ao menos uma parte da crise dessas ações judiciais decorre de uma estratégia da advocacia pública de incentivar os julgadores a se afastar da legislação de regência. Nesse sentido, a súmula 314, bem como o resultado do Recurso Especial n. 1.120.295/SP, ambos do Superior Tribunal de Justiça, inovaram o ordenamento jurídico, sem alteração legislativa, comprovando a estratégia mencionada.

Ambas as decisões acarretaram que sentenças de extinção de execuções fiscais, quer por prescrição intercorrente, quer por prescrição tributária, fossem reformadas, aumentando o estoque de tais feitos. Contudo, ainda que tenham evitado a confirmação da prescrição, manipulado indevidamente a legislação e aumentado o estoque de tais 
feitos, essa estratégia se mostrou equivocada. Ela aumentou um problema nacional (a fraca percepção do Estado Democrático de Direito) e não concentrou forças na verdadeira origem do problema (no caso específico das execuções fiscais, a demora no ajuizamento dos processos). Além disso, sequer se pode dizer que melhorou a arrecadação. Isso porque tal estratégia conseguiu reativar processos antigos nos quais os devedores já não haviam sido encontrados ou não possuíam bens penhoráveis.

Esse quadro de estratégias equivocadas, que não se concentram na origem dos problemas, e sim em soluções no mais das vezes burocráticas, tem sido a tônica de diversas atuações estatais, que contribuem para as crises mencionadas.

\section{Conclusão}

Considerando que pesquisas econômicas indicam que as nações mais desenvolvidas são aquelas onde o Estado Democrático de Direito é mais significativo, conclui-se que o caminho é o fortalecimento do respeito às normas jurídicas, não o afastamento delas ou sua mudança casuística. Nesse contexto, a atuação da advocacia pública nas execuções fiscais pode ser um excelente ambiente para se fortalecer o respeito à Constituição e às leis, auxiliando outras áreas de nossa sociedade a saírem da grave crise que está enfraquecendo a esperança dos brasileiros, em que se nota mais o descumprimento da legislação do que a necessidade de novos diplomas legais. 


\section{Referências bibliográficas}

ACEMOGLU, Daron, ROBINSON, James. Por que as nações fracassam. (e-book) São Paulo: Elsevier, 2012.

BATISTA JÚNIOR, Onofre Alves, OLIVEIRA, Ludmila Mara Monteiro de, MAGALHÃES, Tarcísio Diniz. "Liberalismo, desigualdade e direito tributário". Revista Brasileira de Estudos Políticos, n. 110, pp. 217-272, 2015.

BRASIL. Agência Brasil. Com 726 mil presos, Brasil tem a terceira maior população carcerária do mundo. (2017a). Disponível em http://agenciabrasil.ebc.com.br/geral/ noticia / 2017-12/ populacao-carceraria-do-brasil-sobe-de-622202-para-726712-pessoas. Acesso em 28/02/2018.

BRASIL. Conselho Nacional de Justiça. Justiça em Números 2010. (2010a). Disponível em http:// www.cnj.jus.br/images/programas/justica-em-numeros/rel_sintetico_jn2009. pdf. Acesso em 12/03/2018.

BRASIL. Conselho Nacional de Justiça. Justiça em Números 2013. (2013a). Disponível em

http:/ / www.cnj.jus.br/images/pesquisas-judiciarias/ Publicacoes/relatorio_jn2013.pdf. Acesso em 16/03/2018.

BRASIL. Conselho Nacional de Justiça. Justiça em Números 2017. (2017b). Disponível em http://www.cnj.jus.br/ programas-e-acoes/pj-justica-em-numeros. Acesso em 07/03/2018.

BRASIL. Controladoria Geral da União. Relatório de avaliação da execução de programas de governo n. 21: apuração, inscrição e execução da dívida ativa da União. (2013b). Disponível em http://sistemas.cgu.gov.br/relats/uploads/5459_Relatorio_PGFN_20052013.pdf. Acesso em 25/09/2013. 
BRASIL. Lei $\mathrm{n}^{\circ}$ 6.830, de 22 de setembro de 1980. (1980). Disponível em http://www.planalto.gov.br/CCivil_03/ leis/L6830.htm. Acesso em 16/03/2018.

BRASIL. Procuradoria Geral da Fazenda Nacional. Balanço Geral da União - 2010. (2010b). Disponível em www.pgfn. gov.br/divida-ativa-da-uniao/dados-estatisticos. Acesso em 17/03/2018.

BRASIL. Receita Federal. Carga Tributária no Brasil 2016. (2016). Disponível em http://idg.receita.fazenda.gov.br/ dados/receitadata/estudos-e-tributarios-e-aduaneiros/ estudos-e-estatisticas/carga-tributaria-no-brasil/carga-tributaria-2016.pdf. Acesso em 08/03/2018.

BRASIL. Receita Federal. Estudo sobre Impactos dos Parcelamentos Especiais. (2017c). Disponível em http://idg.receita. fazenda.gov.br/dados/20171229-estudo-parcelamentos-especiais.pdf. Acesso em 09/03/2018.

BRASIL. Receita Federal. PGFN disponibiliza edição 2017 do "PGFN em números". (2017d). Disponível em http:/ / www. fazenda.gov.br/noticias/2017/fevereiro/pgfn-disponibiliza-edicao-2017-do-201cpgfn-em-numeros201d. Acesso em 09/03/2018.

BRASIL. Senado Notícias. Representante da Receita Federal questiona MP que refinancia dívidas de estados e municípios. (2017e). Disponível em https://www12.senado.leg.br/ noticias/materias/2017/06/28/representante-da-receita-federal-questiona-mp-que-refinancia-dividas-de-estados-e-municipios. Acesso em 08/03/2018.

BRASIL. Superior Tribunal de Justiça. Recurso Especial $n$. 1.120.295-SP. (2010c). $1^{\text {a }}$ Seção, Rel. Min. Luiz Fux. Un. J. 12/05/2010, publ. 21/05/2010. 
BRASIL. Superior Tribunal de Justiça. Recurso Especial $n$. 1.120.295-SP. (2010d). Consulta ao processo físico. Inédito. BRASIL ECONÔMICO. Receita recebeu mais de 28,5 milhões de declarações do Imposto de Renda. (2017). Disponível em http:/ / economia.ig.com.br/2017-04-29/ declaracoes-imposto-renda.html. Acesso em 08/03/2018.

CASTRO, Alexander de. "Max Weber e a história do direito: Fundamentos empíricos e historiográficos da sociologia jurídica weberiana", Revista Brasileira de Estudos Políticos, n. 112, pp. 11-65, 2016.

ELIAS, Norbert. O processo civilizador. Trad. Ruy Jugmann. Rev. e apres. Renato Janine Ribeiro. Rio: Jorge Zahar, 1990.

GRAU, Eros R. Por que tenho medo dos juízes (a interpretação/ aplicação do direito e os princípios). 6. ed. refundida de Ensaio e discurso sobre a interpretação/aplicação do direito. São Paulo: Malheiros, 2013.

HUXLEY, T. H. The advance of science in the last half-century. New York: D. Appleton, 1889 (ebook). Disponível em http:/ / www.gutenberg.org/files/15253/15253-h/15253-h. htm. Acesso em 16/03/2018.

SICHES, Luis Recasens. Tratado general de filosofia del derecho. México: Porrua, 1965.

WIKIPEDIA. Lista de países por carga tributária. (2018). Disponível em https://pt.wikipedia.org/wiki/Lista_de_ pa\%C3\%ADses_por_carga_tribut\%C3\%A1ria. Acesso em 08/03/2018.

WORLD JUSTICE PROJECT. WJP Rule of Law Index 2015. Disponível em https://worldjusticeproject.org/sites/ default/files/documents/roli_2015_0.pdf. Acesso em $16 / 03 / 2018$. 
WORLD JUSTICE PROJECT. WJP Rule of Law Index 2016. Disponível em https://worldjusticeproject.org/sites/default/files/documents/RoLI_Final-Digital_0.pdf. Acesso em 16/03/2018.

Recebido em 20/03/2018.

Aprovado em 25/04/2018.

Renato Becho

E-mail: renatobecho@uol.com.br 
